\title{
Some Relationships among Different Ways of Increasing Rational Knowledge
}

\author{
Mario De Marchi \\ CNR-IRCRES, Consiglio Nazionale delle Ricerche-Istituto di Ricerca sulla Crescita Economica Sostenibile, Roma, Italy \\ Email: mario.demarchi@hotmail.com
}

How to cite this paper: De Marchi, M. (2020). Some Relationships among Different Ways of Increasing Rational Knowledge. American Journal of Industrial and Business Management, 10, 1139-1143. https://doi.org/10.4236/ajibm.2020.106076

Received: May 23, 2020

Accepted: June 14, 2020

Published: June 17, 2020

Copyright (c) 2020 by author(s) and Scientific Research Publishing Inc. This work is licensed under the Creative Commons Attribution-NonCommercial International License (CC BY-NC 4.0). http://creativecommons.org/licenses/by-nc/4.0/ (c) (7) \&) Open Access

\begin{abstract}
A geometrical model is presented here which seems to allow some original considerations regarding the scope and results of Science and Technology (S\&T) activities, aimed at searching new rational knowledge. Was this approach validated? It may result in deeper thoughts over the nature of such activities and their reciprocal relationships.
\end{abstract}

\section{Keywords}

Methodology of Science, Science, Technology, S\&T Activities

\section{Introduction}

Scientific research and technological innovation are featured among the main modes that mankind adopts to increase its own rational knowledge. This fact makes all the way more appropriate to define, classify and gauge each scientific/technological activity rationally. In a previous article (De Marchi, 2019), we presented an eight-category taxonomy which aimed at such a target. In the present contribution we aim to develop the classification, which, per se, is just a means of labelling things, into a tool for thought and deeper analysis.

\section{Organization of the Work}

The article's presentation is organized as follows:

- In Section Three a work describing the eight-category Taxonomy of Science and Technology (S\&T) activities already published is recalled through an immediate, graphical representation of the Taxonomy (namely the geometrical "Octahedron of S\&T"). So, it will prove easier to describe certain possible relationships linking different Research and Innovation (R\&I) activities-which are normally measured according to standards and procedures 
established by OECD in its fundamental Frascati (OECD, 2015) e Oslo (OECD, 2018) Manuals;

- In Section Four, we will elucidate some connections shown by those twins of S\&T activities which take up special places within the Octahedron and therefore have particular characteristics;

- Section Five ends the article; in it some crucial features of the interactions among S\&T activities are summed up and a basic principle for the progress of rational knowledge is put forth: scientists' freedom.

\section{Our Taxonomy of S\&T Activities...}

Our Taxonomy begins from an irrefutably essential characteristic of all S\&T activities: both the (abstract) science and the (practical) technology aim at reaching |REPRODUCIBLE - RESULTS|.

S\&T activities therefore consist in a search for |GENERAL - SOLUTIONS|. Three couples of twin traits can be derived from the |GENERAL · SOLUTIONS| binary relationship by simultaneously allowing for the |Science versus Technology| divide:

$\S$ General versus Particular; $₫$ Abstract versus Practical; $₫$ Questions versus Answers.

Given these possible features, S\&T activities may: face either Questions or provide Answers which show either Abstract or Practical and possess either General or Particular nature.

These possible combinations result in eight neatly distinct S\&T activities:

- "Contemplative science", consisting in the investigation of |general - abstract - questions|;

- "Finalized research on general questions", i.e. the S\&T activity specified by the triplet: |general • practical • questions|;

- "Scholarly literature", collecting the outcomes of S\&T activities which result in: |general · abstract • answers|;

- “Technological innovations", namely S\&T activities, which have led to: |general · practical · answers|;

- "Experimental science", which tries providing |particular • abstract • answers| by looking for new empirical observations;

- "Engineering", or those S\&T activities that might produce |particular • practical · answers|;

- "Statistical induction", namely the search for new knowledge by scientists working on |particular • abstract • questions|;

- "Finalized research on particular questions", the S\&T activity defined by the triplet |particular • practical • questions|.

The taxonomy built such way brings about a certain order into the presentation of the several definitions and descriptions which OECD collects in its manuals on S\&T activities' measurement. However, this taxonomy can be represented in a graphical way which makes even simpler, the understanding of the possible relationships linking S\&T activities. 


\section{... and Its Graphical Representation}

The Taxonomy's features can graphically be transposed thanks to a geometric solid possessing six apices (one for each binary characteristic of S\&T) and eight (identical) triangular facets corresponding to the different S\&T activities making up the overall classification: i.e. the "(regular) Octahedron of S\&T activities".

Several relationships, which may be conceived starting from the eight-fold Taxonomy, among the different S\&T activities show up in a more transparent way now.

On the basis of the geometric representation provided through the Octahedron, each of such connections may be:

1) a nexus of contiguity, concerning those $S \& T$ activities represented by couples of (adjacent) facets sharing a border; whereby somewhat vague speculations may be put forward;

2) a link of mere proximity, regarding S\&T activities represented by couples of (tangent) facets sharing a dot, whereby even less precise hypotheses could be derived;

3) a logical relationship of clearer distinction, taking place for those S\&T activities represented by parallel twin facets, namely those corresponding to triplets of apices (features graphically described by these dots) completely disjointed, with respect to which conjectures possessing an empirical content sharper and more easily testable.

In the final part of this article we focus on the class of the relationships indicated in (3). The reason for this choice is the circumstance that, just for their higher precision and clarity, any future conjectures concerning such category, were they corroborated, might imply prescriptions for public R\&I policies with effects greater and more easily checkable.

\section{Supplementary S\&T Activities}

The reader will find no difficulty in imagining, keeping in mind Figure 1,

$$
\begin{aligned}
& \text { APICES } \\
& A=\text { GENERAL } \\
& B=\text { PRACTICAL } \\
& C=\text { PARTICULAR } \\
& D=\text { ABSTRACT } \\
& E=\text { QUESTIONS } \\
& F=\text { ANSWERS }
\end{aligned}
$$

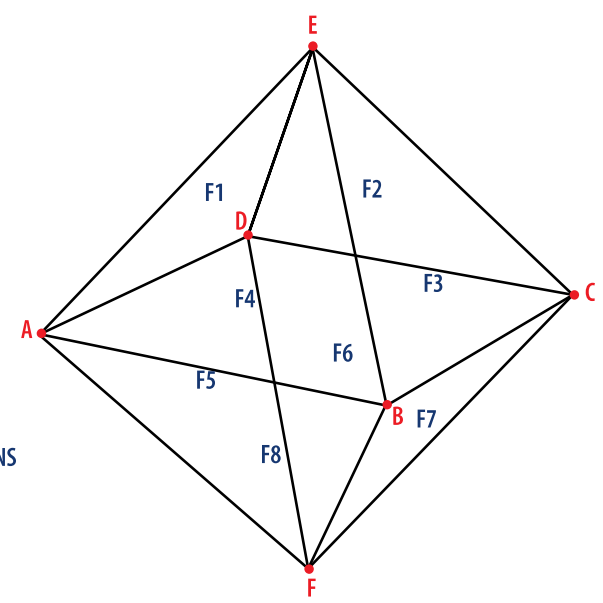

FACETS

$\mathrm{F} 1=$ CONTEMPLATIVE SCIENCE $\mathrm{F} 2=$ STATISTICAL INDUCTION

F3 = FINALISED RESEARCH ON PARTICULAR QUESTIONS

F4= FINALISED RESEARCH ON GENERAL QUESTIONS

F5 $=$ SCHOLARLY LITERATURE

F6 $=$ EXPERIMENTAL SCIENCE

F7 $=$ ENGINEERING

F8 $=$ TECHNOLOGICAL INNOVATIONS

Figure 1. The "Octahedron of Scientific and Technological Activities". 
how the Octahedron may be decomposed into two symmetric pyramids sharing a common base, the higher pyramid originating from the apex "Questions" and the lower one converging towards the apex "Answers". In abstract, therefore, S\&T activities mirrored by the inferior pyramid and the higher one are caused by distinct needs. Nonetheless, in practice these two sorts of activities cover conjunct issues; so, it can happen, or rather it will frequently happen, that as rational knowledge grows answers or questions originated by an S\&T activity foster new search elsewhere and they be just those in abstract "counterpoised" activities which more strongly benefit of such progress. Below, we are going to provide some examples of this "cross-breeding".

\section{1) $\underline{\text { Statistical Induction }} \cdot \underline{\text { Technological Innovation }}$}

A phenomenon in-depth analyzed by economists is the one labelled as learning-by-using. At the beginnings of the Industrial Revolution, the generalization by induction of empirical observations about the working of steam engines promoted the introduction of more efficient motors (and afterwards the intuitions on Thermodynamics by Carnot).

\section{2) Scholarly Literature $\bullet$ Finalized research on Specific questions}

An example of a close logical, if not chronological, link between a "publication" and "finalized research on a specific question" concerns Newcomen, (who took inspiration from the work by Papin about Heron's ideas: the "papers" by the last researcher allowed the first one to provide an answer to the specific question "how to keep a mine dry without using human or animal power?". The circumstance that more than a millennium's time went by between the original idea and application should make the policy-makers and the stake-holders of research systems all the more patient and forbearing towards scientists and technicians.

\section{3) Contemplative Science • Engineering}

Usually, thinking about possible relationships between Contemplative Science and Engineering examples come to mind concerning disciplines such as Rational Mechanics, from whose formulas engineers work out specific applications in industries like Aeronautics. However, the nexus between these two S\&T activities plays a crucial role in other sectors as well, sometimes unsuspected at first sight. Let us consider, for instance, that Engineering masterpiece (on which is based large part of Electronics), the transistor: it would have not been possible without the knowledge obtained thanks to Quantum Mechanics.

\section{4) Experimental science $\bullet$ Finalized research on General questions}

In the history of science and technology, examples do abound of reciprocal interactions between these two activities. On one side, for instance, the invention of the telescope allowed Galileo to make new astonishing and revolutionary empirical observations. On the other side, the need for more and more advanced magnets, adopted by the ever more powerful particle accelerators utilized for experimental search within Particle Physics, has substantially fostered finalized research activities on superconducting materials. 


\section{Lessons for Science Policy: Which Incentives to Scientists for Steering R\&I Systems?}

The Octahedron is a synthetic, perhaps even elegant, representation of some characters and relationships concerning "S\&T Activities". However, such activities consist in the Scientists and Technicians by whom they are performed. It is the people, the researchers, who produce new rational knowledge, of course. But the simplified, geometrical representation of categories perhaps may have some interest. It allows seeing more easily what could remain hidden away even to the scientist, entangled by the passion for knowledge: namely, that the work a researcher performs, by perpetually moving within the epistemic space which the Octahedron delimits, consists in a combination of several, essentially heterogenous and demanding intellectual works, done while complying with reciprocally opposite targets.

The scholar dealing with Science Policy can immediately draw a clear lesson from these considerations. A Research System ought not to be governed through a strict application of the Principle of Authority, be it exercised by the scientists in the higher ranks of academia or even policy-makers themselves. Rather, efforts should be made to grant researchers the prizes they long for.

And scientists moved by genuine interests for knowledge will hardly appreciate anything more than liberty: freedom to make public and possibly apply the results of their own research activities. Therefore, a fundamental criterion of both public and private policy makers' missions shall be to build and rule the institutions of a research system by constantly fighting against the establishment of a too rigid hierarchy (Feyerabend, 1988) and the censorship of new ideas it tends to bring about within Science, by getting in the way of criticizing accepted knowledge, proposing original theories, performing new experiments. Instead, each scientist's ideas should be allowed a chance of competing fairly with the colleagues'.

\section{Conflicts of Interest}

The author declares no conflicts of interest regarding the publication of this paper.

\section{References}

De Marchi, M. (2019). Indicators OECD Proposes for Gauging Science \& Technology, American Journal of Industrial and Business Management, 9, 2078-2082. https://doi.org/10.4236/ajibm.2019.911137

Feyerabend, P. (1988). Against Method. London: Verso.

OECD (2015). Frascati Manual (Guidelines for Collecting and Reporting Data on Research and Experimental Development). Paris: OECD. https://doi.org/10.1787/9789264268111-ko

OECD (2018). Oslo Manual (The Measurement of Scientific, Technological and Innovation Activities). Paris: OECD. 